\title{
MAL Expression in Lymphoid Cells: Further Evidence for MAL as a Distinct Molecular Marker of Primary Mediastinal Large B-Cell Lymphomas
}

Christiane Copie-Bergman, M.D., Anne Plonquet, M.D., Miguel A. Alonso, Ph.D., Marie-Laure Boulland, Ph.D., Jeanine Marquet, Ph.D, Marine Divine, M.D., Peter Möller, M.D., Karen Leroy, M.D., Ph.D., Philippe Gaulard, M.D.

Département de Pathologie, Service d'Immunologie Biologique, Service d'Hématologie Clinique, Hôpital Henri Mondor, Créteil, France; Centro de Biología Molecular "Severo Ochoa," Universidad Autónoma de Madrid and Consejo Superior de Investigaciones Científicas, Madrid, Spain; and Institute of Pathology, University of Ulm, Ulm, Germany

The MAL mRNA was initially identified during T-cell development and was later found in myelinforming cells and certain polarized epithelial cell lines. It encodes a proteolipid believed to participate in membrane microdomains stabilization, transport machinery and signal transduction. Using a differential display reverse-transcription approach, we identified MAL as a distinct molecular marker of primary mediastinal large B-cell lymphoma compared with nonmediastinal diffuse large B-cell lymphomas. In the present study, we used immunohistochemistry to extend MAL expression analysis to normal lymphoid tissues; to $185 \mathrm{lym}$ phomas representing most $B, T$, and Hodgkin lymphoma entities; and to the primary mediastinal large B-cell lymphoma derived B-cell line MedB-1. In addition, $B$ and $T$ cells from peripheral blood, tonsil, and spleen were analyzed by flow cytometry. Our results show that MAL is highly expressed in thymocytes, in a large percentage of peripheral CD4 $T$ cells, and in a lower proportion of $\mathrm{CD8}$ peripheral $T$ cells. In the normal B-cell compartment, MAL expression appears to be restricted to a minor subpopulation of thymic medullary $B$ cells and to occasional mature plasma cells located in the interfollicular areas of tonsil and lymph nodes. Among B-cell lymphomas $(n=110)$, MAL expression in

Copyright (C) 2002 by The United States and Canadian Academy of Pathology, Inc.

VOL. 15, NO. 11, P. 1172, 2002 Printed in the U.S.A.

Date of acceptance: July 20, 2002.

M.A.A. is supported by grants from the Dirección General de Enseñanza Superior (PM99-0092), and Fondo de Investigación Sanitaria (01/008501). An institutional grant from the Fundación Ramón Areces to the Centro de Biología Molecular "Severo Ochoa" is also acknowledged. Address reprint requests to: Christiane Copie-Bergman, M.D., Département de Pathologie, Hôpital Henri Mondor, 51 avenue du Maréchal de Lattre de Tassigny, 94010 Créteil, France; e-mail: christiane.copie@ hmn.ap-hop-paris.fr; fax: 33-1-4981-2733.

DOI: $10.1097 / 01 . M P .0000032534 .81894 . B 3$ tumor cells was observed in 21/33 primary mediastinal large B-cell lymphomas $(70 \%)$ and in $3 / 5$ plasmacytoma/myeloma, but not in all other B-cell lymphomas with the exception of $1 / 33$ nonmediastinal diffuse large B-cell lymphomas. The MedB-1 B-cell line was also MAL positive. Among T-cell neoplasms, MAL was highly expressed in lymphoblastic tumors (5/6), whereas mature T-cell lymphomas were essentially MAL negative (27/28). Among 41 Hodgkin lymphomas, 3 nodular-sclerosing cases with mediastinal involvement showed MAL-positive Reed Sternberg cells. In conclusion, this study further supports thymic $B$ cells as the putative normal counterpart of primary mediastinal large B-cell lymphomas and supports MAL as a distinct molecular marker of this lymphoma subtype among diffuse large B-cell lymphomas.

KEY WORDS: B-cell lymphoma, Hodgkin lymphoma, Lymphoid cells, MAL.

Mod Pathol 2002;15(11):1172-1180

MAL mRNA was initially identified by a differential screening approach during the search for T-cell maturation-associated cDNAs and was shown to be associated with the intermediate and later stages of intrathymic T-cell differentiation (1). Subsequently, MAL expression was observed in rat myelinforming cells (2) and in polarized epithelial cell lines derived from dog kidney and rat thyroid $(3,4)$. MAL is an integral membrane protein located in glycolipid-enriched membrane microdomains, called lipid rafts, and is believed to participate in membrane microdomains' stabilization, transport machinery, and signal transduction (5-10).

Using a differential-display reverse transcription approach, we identified MAL as a distinct molecular marker of primary mediastinal large B-cell lym- 
phomas compared with nonmediastinal diffuse large B-cell lymphomas (11). MAL recurrent expression in primary mediastinal large B-cell lymphomas was confirmed by Northern blot, reverse transcription-polymerase chain reaction (RT-PCR), and immunohistochemical studies in a limited series of primary mediastinal large B-cell lymphomas, nonmediastinal diffuse large B-cell lymphomas, and neoplastic B-cell lines. These results were in line with the hypothesis that primary mediastinal large B-cell lymphoma represents a distinct lymphoma subtype among diffuse large B-cell lymphomas (12).

According to the literature, MAL protein is expressed in lymphoid cells derived from the T-cell lineage (thymus, peripheral blood T-cells, $\mathrm{CD} 4^{+} \mathrm{CD} 8^{-}$helper, and $\mathrm{CD}^{-}{ }^{-} \mathrm{CD} 8^{+}$cytotoxic mature $\mathrm{T}$-cell clones and leukemic $\mathrm{T}$-cell lines) but is not expressed in the B-cell lineage $(1,10,13,14)$. However, extensive studies of MAL protein expression in normal lymphoid tissues and lymphoid malignancies have not been performed yet. The aims of our study were first to analyze the pattern of MAL expression in peripheral blood lymphocytes and normal lymphoid tissues, including the thymus, tonsil, reactive lymph node, and spleen and secondarily, to further extend the immunohistochemical analysis of MAL protein expression to a large series of B- and T-cell lymphoid malignancies and to the primary mediastinal large B-cell lymphomaderived B-cell line MedB-1 (15).

\section{MATERIALS AND METHODS}

\section{Flow Cytometry}

Peripheral blood was obtained from blood donors and handled according to established clinical guidelines. Tonsils were obtained from children operated on for benign reactive hyperplastic tonsils. Spleen samples were obtained from patients undergoing splenectomy as treatment against immune thrombocytopenic purpura. Peripheral mononuclear cells and mononuclear cells obtained after dilaceration of tonsil or spleen were isolated on Ficoll preparations and frozen in dimethylsulfoxide until use.

The following monoclonal antibodies (mAb) were used: CD3(HIT3 $\alpha$ ) and CD19(HD 237), both directly conjugated to phycoerythrin-Texas Red (ECD) from Beckman-Coulter (Hialey, FL), CD4(53-5; Tricolor) from Caltag (Burlingame, CA). Anti-MAL 6D9 mAb directed against amino acids 114-123 of the human MAL protein (4; gift from Miguel Alonso, Madrid, Spain) was used in an indirect staining in combination with GAM-F(ab') ${ }_{2}$ FITC (fluorescein isothiocyanate) anti IgG (H+L; Tebu, Le-Perray-enYvelines, France) as secondary antibody. Briefly, cells were thawed in RPMI plus fetal calf serum (FCS), washed once, and incubated 15 minutes at $4^{\circ}$ $\mathrm{C}$ with the directly conjugated surface monoclonal antibodies for lymphocyte subset determination. After washing once, cells were permeabilized in phosphate-buffered saline (PBS) containing 0.1\% saponin and FCS at 5\%. MAL antibody or controlirrelevant primary antibody was added, and cells were incubated for 30 minutes at $4^{\circ} \mathrm{C}$. After two washes, secondary antibody was added for another incubation of 15 minutes at $4^{\circ} \mathrm{C}$.

Irrelevant murine monoclonal antibodies were used to define background staining: IgG2aphycoerythrin, IgG2b-ECD, from Beckman-Coulter, IgG2a-Tricolor from Caltag, and total mouse Ig (Tebu) with GAM-FITC as a negative control for MAL staining. MAL/CD19 and MAL/CD3/CD4 multiple labeling were performed to assess expression of MAL in B- and T-cell subsets of peripheral blood, tonsils, and spleens. Lymphocytes were identified by forward- and side-scatter analysis. CD4 T cells were defined as $\mathrm{CD}^{+}{ }^{+} \mathrm{CD}^{+}$cells, $\mathrm{CD} 8 \mathrm{~T}$ cells as $\mathrm{CD}^{-} \mathrm{CD}^{+}$cells, and B cells as $\mathrm{CD} 19^{+}$cells. Light compensation for each combination of antibodies had been established in our laboratory before this study. Flow cytometry was performed with a Coulter EPICS® XL within 24 hours from the staining. Listmode parameters were analyzed and stored on System II software (Beckman-Coulter).

\section{Histology and Immunohistochemistry}

Eight samples of reactive lymphoid tissues were studied: two tonsils, two spleens, two reactive lymph nodes, and two thymuses (one neonatal and one from a 19-year-old man). All were fixed in Bouin's fixative, paraffin embedded, and routinely processed. An additional portion of one of the two thymuses was also snap-frozen in liquid nitrogen and stored at $-80^{\circ} \mathrm{C}$ for phenotypic studies.

One hundred eighty-five cases of lymphoid malignancies were retrieved from the files of the Department of Pathology, Henri Mondor hospital, Créteil, France. Material consisted of Bouin's-, formalin-, or AFA (alcohol, formalin, and acetic acid)-fixed pathological specimens. Paraffinembedded tissue sections were stained with hematoxylin-eosin for histological studies. Lymphomas were classified according to the World Health Organization classification (16) using both morphological and immunophenotypic criteria. This series included 33 cases of primary mediastinal large B-cell lymphomas, 33 cases of nonmediastinal large B-cell lymphomas, and most B- and T/NK-cell neoplasms and comprised the 12 cases of primary mediastinal large B-cell lymphomas and the 8 cases of nonmediastinal diffuse large B-cell lymphomas analyzed for MAL expression in our initial study 
(11). Pathological specimens of primary mediastinal large B-cell lymphoma consisted of 27 mediastinal biopsies and 6 peripheral lymph node biopsies. Specimens of nonmediastinal diffuse large B-cell lymphomas included 28 peripheral lymph node biopsies, 2 extranodal diffuse large B-cell lymphomas (spleen and small bowel), and 3 cases of pyothorax-associated B-cell lymphomas.

This series also included 31 cases of classical Hodgkin lymphoma and 10 cases of nodular lymphocyte-predominant Hodgkin lymphoma. Among classical Hodgkin lymphomas, 25 patients presented with mediastinal disease and 2 patients without; this information was not available for 4 patients. Pathological specimens of classical Hodgkin lymphomas consisted of mediastinal biopsies for 6 cases and of peripheral lymph nodes for the remainders.

Immunohistochemistry was performed on paraffinembedded tissue sections using the Ventana automated immunostainer (Ventana Medical Systems, Tucson, AZ) and their diaminobenzidine detection kit, according to the manufacturer's recommendations. All cases were evaluated for B- and T-cell differentiation antigens. When appropriate, antigen retrieval was performed by microwave heating in citrate or EDTA buffer.

MAL protein expression was evaluated using anti-MAL 6D9 mAb. Variable intensity of the MAL immunostaining was observed depending on the fixative used: Bouin's fixative appeared to be the best fixative to preserve MAL immunoreactivity. In contrast, EDTA or citrate pretreatment were necessary for formalin or AFA-fixed specimens to highlight MAL immunoreactivity. Therefore, most cases were evaluated in triplicate in various conditions: without pretreatment, microwave heating in citrate buffer (12 min at $750 \mathrm{~W}, 2$ times for $10 \mathrm{~min}$ at $350 \mathrm{~W}$ in citrate buffer, $\mathrm{pH}$ 6.7), and microwave heating in EDTA buffer (12 min at 750W, 3 times for $10 \mathrm{~min}$ at 350W in EDTA buffer, pH 8.0). The pattern of MAL immunoreactivity consisted of membrane with or without paranuclear dotlike staining of the tumor cell. Intratumoral positive small lymphoid cells consistent with reactive $\mathrm{T}$ cells were present in all cases. Samples without internal positive control were considered noninterpretable and were excluded from the study.

Cytospin preparations of MedB-1 mediastinal B-cell line (15) were also evaluated for MAL protein expression by immunocytochemistry using the Ventana automated immunostainer.

Expression of MAL together with B-cell marker CD79a were evaluated in thymus, tonsil, and reactive lymph node paraffin-embedded tissue sections using double immunofluorescence labeling. Frozen sections of one of the thymuses were also evaluated. Briefly, paraffin-embedded tissue sections were dewaxed and microwave pretreated in citrate buffer, as described previously. Frozen tissue sections were fixed in acetone for 10 minutes. Slides were first incubated with $10 \%$ goat serum (Santa Cruz, Tebu, Le-Perray-en-Yvelines, France) for 20 minutes, followed by primary anti-MAL 6D9 mAb (IgG2a) at 1:50 dilution for 1 hour. After PBS washes, slides were incubated in the dark with goat anti-mouse IgG-Cy3 antibody (Caltag, Tebu, LePerray-en-Yvelines, France) at 1:50 dilution for 30 minutes. After PBS washes, slides were incubated with secondary anti-CD79a antibody (IgG1; Dako, SA, Glostrup, Denmark) at 1:50 dilution for 1 hour. Slides were washed in PBS and then incubated with goat anti-mouse IgG1-FITC antibody (Santa Cruz, Tebu, Le-Perray-en-Yvelines, France) at 1:200 dilution for 30 minutes. After PBS washes, slides were mounted in Vectashield (Vector, Burlingame, CA) medium and kept in the dark at $4^{\circ} \mathrm{C}$ until analyzed. Sections were viewed on a Leica microscope equipped for fluorescence.

\section{RESULTS}

\section{MAL Protein Expression in Peripheral Blood Lymphocytes, Lymphoid Suspensions of Tonsil, and Spleen by Flow Cytometry}

Expression of MAL protein in mature B lymphocytes and in CD4 and CD8 T lymphocyte subsets was assessed by flow cytometry in four peripheral blood lymphocyte samples and in cell suspensions of two tonsils and of two spleens. The results are shown in Table 1 and illustrated in Figure 1. MAL was consistently expressed in a large proportion of CD4 T cells (range: 65-90\%; Fig. 1A), except in one tonsil sample, where MAL expression was lower (31\%). MAL antigen was less frequently expressed in CD8 T cells (range: $22-50 \%$ ) and was very scarce in one spleen sample (5\%). MAL was not significantly expressed in peripheral blood B cells (Fig. 1B) or in B-cell subsets of tonsil and spleen.

\section{MAL Protein Expression in Thymus, Tonsil, Reactive Lymph Node, and Spleen \\ Tissue Sections}

In the thymus, two distinct zones were observed. Lymphoid cells from the thymic cortex were strongly positive for MAL (Fig. 2A). In contrast, the medulla, where most B cells are located (Fig. 2B), displayed occasional MAL-positive lymphoid cells. Squamous epithelial cells from Hassall's corpuscles were also found positive.

The pattern of MAL immunoreactivity was similar in the tonsils and in the reactive lymph nodes. MAL protein expression was restricted to small lymphoid cells that were scattered in the interfollicular 


\begin{tabular}{|c|c|c|c|c|c|c|c|}
\hline Lymphocyte Subset & Sample & $\begin{array}{c}\text { B Cells }^{a} \\
(\%)\end{array}$ & $\begin{array}{c}\text { MAL+ Cells } \\
\text { Among B } \\
\text { Cells (\%) }\end{array}$ & $\begin{array}{c}\text { CD4 } \mathrm{T}^{a} \\
\text { Cells (\%) }\end{array}$ & $\begin{array}{c}\text { MAL+ Cells } \\
\text { among CD4 } \\
\text { T Cells (\%) }\end{array}$ & $\begin{array}{c}\text { CD8 } \mathrm{T}^{a} \\
\text { Cells (\%) }\end{array}$ & $\begin{array}{c}\text { MAL + Cells } \\
\text { among CD8 } \\
\text { T Cells (\%) }\end{array}$ \\
\hline \multirow[t]{4}{*}{ Peripheral blood lymphocytes } & 1 & 8 & 0 & 56 & 65 & 19 & 28 \\
\hline & 2 & 22 & 0.6 & 35 & 85 & 31 & 39 \\
\hline & 3 & 9 & 0 & 48 & 90 & 32 & 26 \\
\hline & 4 & 11 & 0.3 & 40 & 77 & 28 & 22 \\
\hline \multirow[t]{2}{*}{ Tonsil } & 5 & 75 & 1.5 & 16 & 31 & 3.7 & 27 \\
\hline & 6 & 70 & 2 & 22 & 76 & 9 & 50 \\
\hline \multirow[t]{2}{*}{ Spleen } & 7 & 45 & 0.6 & 19 & 70 & 38 & 5 \\
\hline & 8 & 61 & 0.7 & 16 & 90 & 18 & 27 \\
\hline
\end{tabular}

The percentages represent the proportion of positive elements in the lymphocyte gate. Results were obtained by two multiple-labelings, MAL/CD19, and MAL/CD3/CD4 combinations under permeabilization conditions $(0.1 \%$ saponin).

${ }^{a} \mathrm{~B}$ cells were defined as $\mathrm{CD} 19^{+}$cells, CD4 T cells as CD4 ${ }^{+} \mathrm{CD} 3^{+}$cells, and CD8 T cells as $\mathrm{CD} 4^{-} \mathrm{CD} 3^{+}$cells.

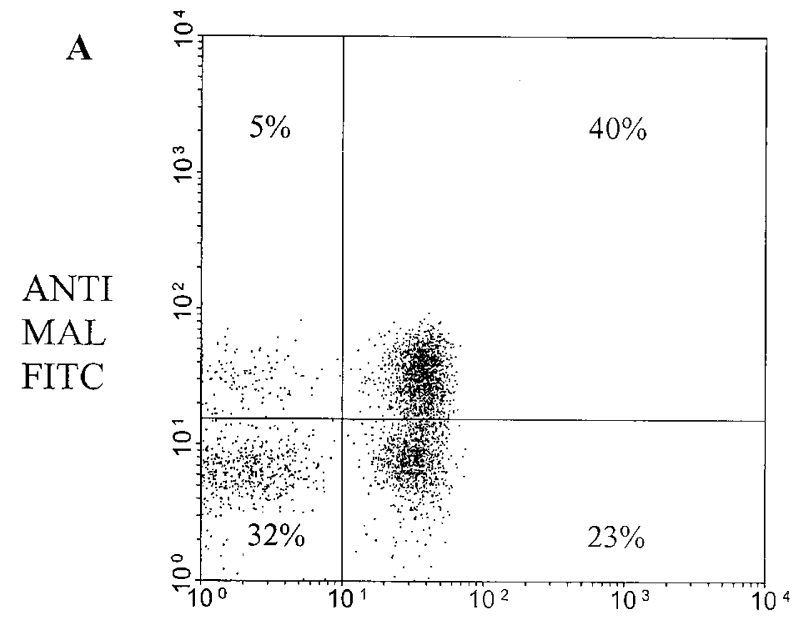

ANTI CD4 TRI

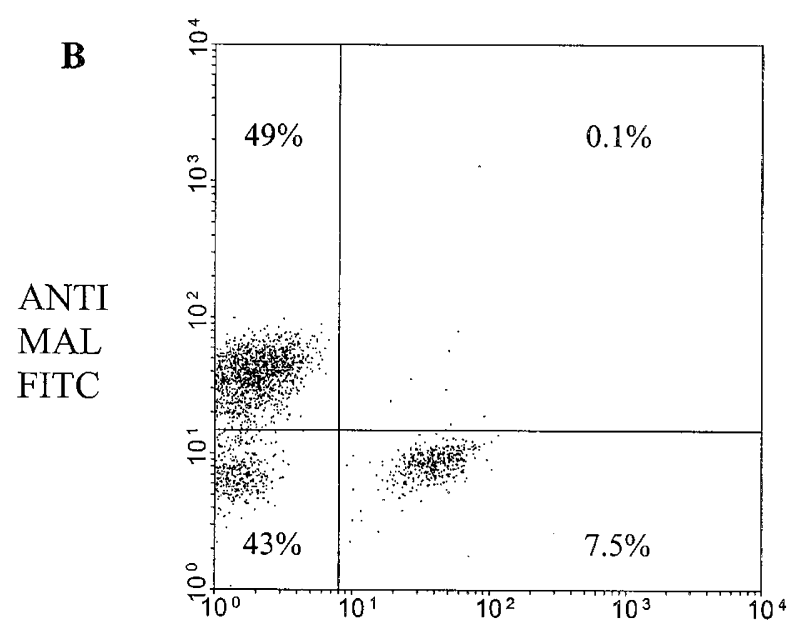

ANTI CD19 ECD

FIGURE 1. Flow cytometry analysis of MAL expression in peripheral blood lymphocyte subsets. After permeabilization with $0.1 \%$ saponin PBS, peripheral blood lymphocytes were double-stained with MAL antibody after permeabilization with $0.1 \%$ saponin PBS and CD4 or CD19 antibody. Analysis was restricted to elements in the lymphocyte gate. A, MAL is expressed in 77\% of CD4+ lymphocytes. B, MAL is not expressed in normal peripheral B lymphocytes.

zone and occasionally located in the germinal center of lymphoid follicles (Fig. 2C). These cells were distinct from centrocytes or centroblasts and presented a pattern consistent with small $\mathrm{T}$ lymphocytes. The number of MAL-positive lymphoid cells was variable from case to case, accounting for about 5 to $30 \%$ of interfollicular small lymphoid cells. In addition, MAL protein expression was also observed in occasional mature plasma cells located in the interfollicular areas, in superficial squamous epithelial cells, and in nerve sections (Fig. 2D). In the spleen, rare positive small lymphoid cells were observed in the red pulp and within the periarterial lymphatic sheath of the white pulp.

Double Immunofluorescence Labeling of Thymus, Tonsil, and Reactive Lymph Nodes Tissue Sections with Anti-MAL and Anti-CD79a Antibodies

Double immunofluorescence labeling of two thymuses revealed that a minor fraction of thymic medullary B cells displayed MAL immunoreactivity. These MAL-positive B cells were either small and round or asteroid shaped (Fig. 3). In tonsil and reactive lymph node tissue sections, occasional plasma cells of the interfollicular areas displayed both CD79a and MAL immunoreactivity.

\section{MAL Protein Expression in Lymphoid Malignancies}

The results are shown in Table 2 and illustrated in Figure 4. Among 33 cases of primary mediastinal large B-cell lymphomas, 21 cases (70\%) demonstrated MAL protein immunoreactivity. The percentage of positive tumor cells ranged from $10 \%$ to virtually all tumor cells (Fig. 4A). Interestingly, the MedB-1 B-cell line was found to be positive for MAL (Fig. 4B). About a third of the cells displayed cytoplasmic and paranuclear dot-like immunoreactivity, with a variable intensity from cell to cell. We did not observe any differences between the MAL- 

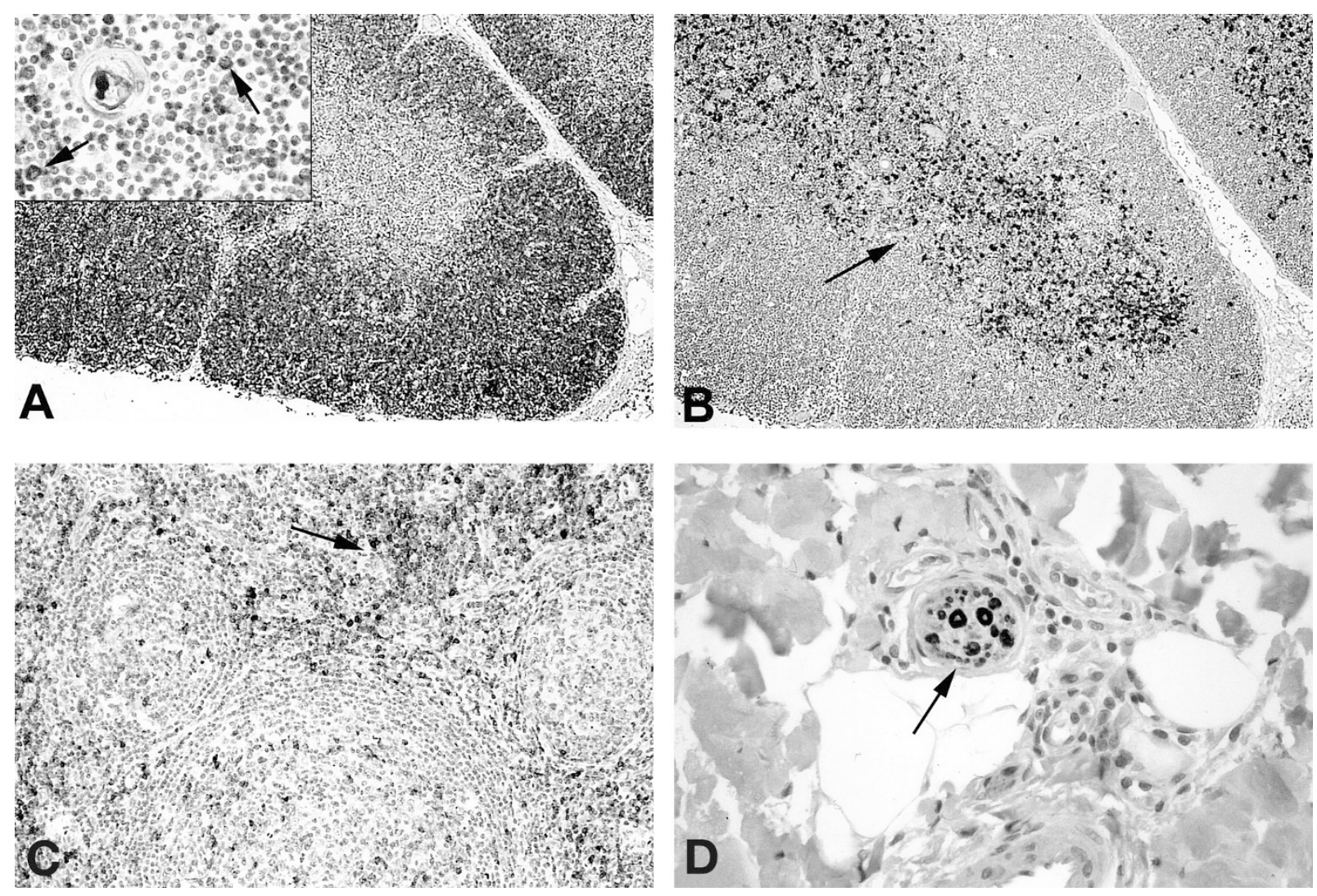

FIGURE 2. Immunohistochemical analysis of thymus, reactive lymph node and nerve tissue sections. A, thymic tissue section showing strong MAL expression in the cortex whereas the medulla displays few positive lymphocytes (arrows) and positive Hassal's corpuscles. B, thymic tissue section stained with anti-CD20 for comparison, showing that thymic B-cells (arrow) are conversely distributed in the medulla. C, reactive lymph node stained with anti-MAL antibody showing scattered positive small lymphocytes in the interfollicular areas (arrow) and occasionally in the germinal center. D, nerve section positive for MAL (arrow).

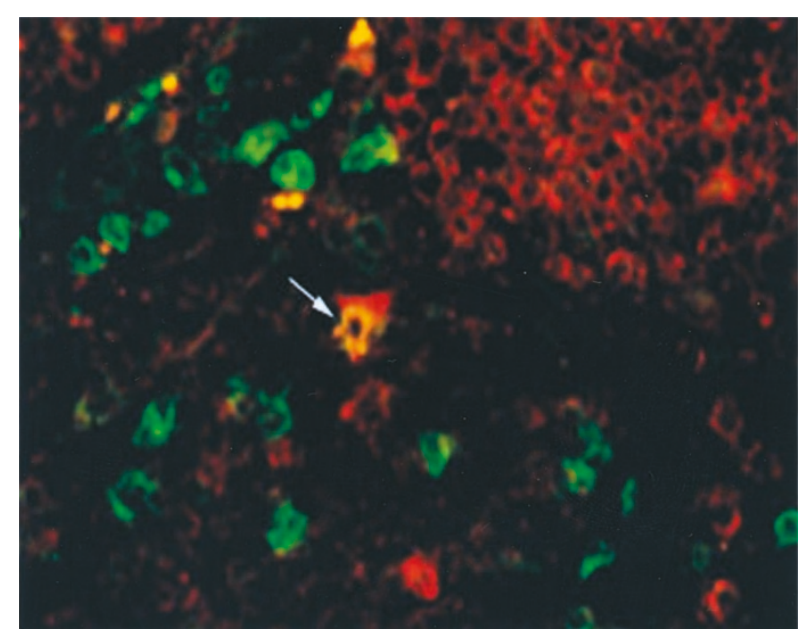

FIGURE 3. Double immunofluorescence labeling of paraffinembedded thymic tissue sections with anti-MAL and anti-CD79a antibodies. Staining for MAL (red) picks out the cortex on the right, which is highly positive, and occasional MAL-positive cells in the medulla (left and below). Staining for CD79a (green) picks out thymic B cells which are located in the medulla. One asteroid-shaped B cell displays MAL immunoreactivity (arrowhead) giving a yellow signal.

positive and MAL-negative primary mediastinal large B-cell lymphoma cases in terms of histology or immunophenotype. Among 33 cases of nonme- diastinal diffuse large B-cell lymphomas, only one case $(3 \%)$ demonstrated MAL-positive tumor cells. This case was a large B-cell lymphoma of polymorphic centroblastic subtype located in a lymph node, without documented mediastinal location. All other diffuse large B-cell lymphoma cases, as well as Burkitt's lymphomas, remained negative (Fig. 4C).

Tumor cells of all low grade B-cell malignancies, including B-cell chronic lymphocytic leukemia, mantle cell lymphoma, follicular lymphoma (Fig. $4 \mathrm{D})$, and marginal zone lymphoma, were negative for MAL immunostaining. Three of five plasmacytoma/myeloma showed numerous positive tumor cells.

In the T-cell lineage, five of six T-lymphoblastic lymphomas were strongly positive (Fig. 4E). Among peripheral T-cell lymphomas (PTCLs), all cases of PTCLs unspecified, angioimmunoblastic, nasaltype NK/T-, hepatosplenic, and adult T-cell lymphomas HTLV1 + remained negative, except for apparently reactive small lymphocytes. One case of ALK-negative anaplastic large cell lymphoma located in a lymph node demonstrated MAL positivity in the Golgi area of many neoplastic cells.

Most cases (28/31) of classical Hodgkin lymphomas were negative for MAL (Fig. 4F). Three cases 
TABLE 2. Immunohistochemical Analysis of MAL Protein Expression in Lymphoid Malignancies

\begin{tabular}{|c|c|c|c|}
\hline Histology & $\begin{array}{l}\text { No. Cases } \\
\text { Studied }\end{array}$ & $\begin{array}{l}\text { No. Positive } \\
\text { Cases }\end{array}$ & $\begin{array}{l}\text { No. Negative } \\
\text { Cases }\end{array}$ \\
\hline \multicolumn{4}{|l|}{ B-cell lymphoma } \\
\hline B lymphoblastic & 1 & 0 & 1 \\
\hline Small lymphocytic & 6 & 0 & 6 \\
\hline Mantle cell & 6 & 0 & 6 \\
\hline Follicular & 10 & 0 & 10 \\
\hline MZL of MALT type ${ }^{a}$ & 8 & 0 & 8 \\
\hline Splenic or nodal MZL & 3 & 0 & 3 \\
\hline Plasmacytoma/myeloma & 5 & $3(60 \%)$ & 2 \\
\hline Burkitt's lymphoma & 5 & 0 & 5 \\
\hline $\begin{array}{l}\text { Primary mediastinal large } \\
\text { B-cell lymphoma }\end{array}$ & 33 & $21(70 \%)$ & 9 \\
\hline $\begin{array}{l}\text { Non-mediastinal diffuse } \\
\text { large B-cell lymphoma }\end{array}$ & 33 & $1(3 \%)$ & 29 \\
\hline $\begin{array}{c}\text { T-cell and NK-cell } \\
\text { lymphoma }\end{array}$ & \multicolumn{2}{|c|}{ T-cell and NK-cell } & \\
\hline T lymphoblastic & 6 & $5(83 \%)$ & 1 \\
\hline Adult T cell $\left(\mathrm{HTLV}^{+}\right)$ & 2 & 0 & 2 \\
\hline $\begin{array}{l}\text { Peripheral T cell } \\
\text { unspecified }\end{array}$ & 5 & 0 & 5 \\
\hline $\begin{array}{l}\text { Angioimmunoblastic } \mathrm{T} \\
\text { cell }\end{array}$ & 5 & 0 & 5 \\
\hline Anaplastic large cell & 11 & $1(9 \%)$ & 10 \\
\hline Nasal-type NK/T cell & 4 & 0 & 4 \\
\hline Hepatosplenic T cell & 1 & 0 & 1 \\
\hline \multicolumn{4}{|l|}{ Hodgkin lymphoma } \\
\hline Classical Hodgkin & 31 & $3(10 \%)$ & 28 \\
\hline $\begin{array}{l}\text { Nodular lymphocyte } \\
\text { predominant }\end{array}$ & 10 & 0 & 10 \\
\hline
\end{tabular}

MZL, marginal zone lymphoma.

${ }^{a}$ Included two gastric, two pulmonary, three salivary gland, and one thymic cases.

(10\%) of nodular sclerosing subtype, with CD30 ${ }^{+}$, $\mathrm{CD}_{15}{ }^{+}, \mathrm{CD}^{2} 0^{-}$immunophenotype, displayed MAL-positive Reed Sternberg cells that represented $20-50 \%$ of the tumor cells. Those three patients presented with mediastinal involvement, and pathological specimens consisted of subclavicular lymph nodes in two cases and of a thymic mass in the third case. All cases of lymphocytepredominant Hodgkin lymphoma remained negative.

\section{DISCUSSION}

Our study provides additional informations on the pattern of MAL protein expression in the lymphoid lineage in physiologic conditions. Flow cytometry analysis of peripheral blood lymphocytes and of tonsil and spleen lymphoid cell suspensions demonstrated consistent MAL protein expression in the CD4 T-cell subset (range: $65-90 \%$ ) and in a lower fraction of the CD8 T-cell subset (range: 22$50 \%$ ), whereas CD19+ B cells remained essentially negative. In comparison, immunohistochemical studies of normal lymphoid organs showed scattered small lymphoid cells, in the interfollicular areas of tonsils and lymph nodes and in the periarterial lymphatic sheath of the white pulp of the spleen, which were consistent with reactive T-cells.
Occasional positive cells with plasma cell morphology were observed in the interfollicular areas, but centroblasts and centrocytes in germinal centers remained negative.

In the thymus, the pattern of MAL immunoreactivity showed two distinct zones: the cortex, which was strongly positive, and the medulla, where only few positive lymphoid cells were observed. Interestingly, double immunofluorescence labeling of thymus tissue sections with MAL and CD79a mAbs revealed that a minor fraction of thymic medullary B cells, including asteroid-shaped B cells, displayed MAL immunoreactivity. This result is of significant importance because primary mediastinal large B-cell lymphomas are believed to arise from thymic B cells $(17,18)$. The reason that a small fraction of thymic B cells express MAL remains to be elucidated. It may be hypothesized that MAL expression is related to a specific stage of B-cell differentiation. Indeed, thymic B cells have proved to be an heterogeneous population of $\mathrm{B}$ cells in regard to their phenotype and immunoglobulin $\mathrm{V}_{\mathrm{H}}$ gene status, suggesting that some but not all thymic B cells are postgerminal center B cells $(19,20)$. Despite controversies regarding the germinal-center or postgerminal-center derivation of primary mediastinal large B-cell lymphomas $(21,22)$, a recent study has shown that primary mediastinal large B-cell lymphomas present heavily mutated, classswitched immunoglobulin genes without evidence of ongoing mutational activity, favoring their origin from B cells at a terminal stage of differentiation (23). Because MAL expression is found in primary mediastinal large B-cell lymphomas, in plasmacytoma/myeloma, and in occasional plasma cells in normal lymphoid organs, it is tempting to speculate that primary mediastinal large B-cell lymphomas derive from a subset of thymic B cells that express MAL at a terminal stage of differentiation.

In the context of B-cell lymphoproliferations, our results confirm the recurrent expression of MAL protein in primary mediastinal large B-cell lymphomas, as compared with other B-cell malignancies. All low-grade B-cell lymphomas including B-CLL, mantle-cell, follicular, and marginal zone lymphomas were negative for MAL expression. Twenty-one out of 33 primary mediastinal large B-cell lymphomas $(70 \%)$ displayed positive tumor cells, whereas only 1 nonmediastinal diffuse large B-cell lymphoma of $33(3 \%)$ was positive. Moreover, the primary mediastinal large B-cell lymphoma-derived B-cell line MedB-1 recently reported by Möller et al (15) expressed MAL by RT-PCR (data not shown) and immunocytochemistry. Altogether, these results further support MAL as a distinct molecular marker of primary mediastinal large B-cell lymphoma. 

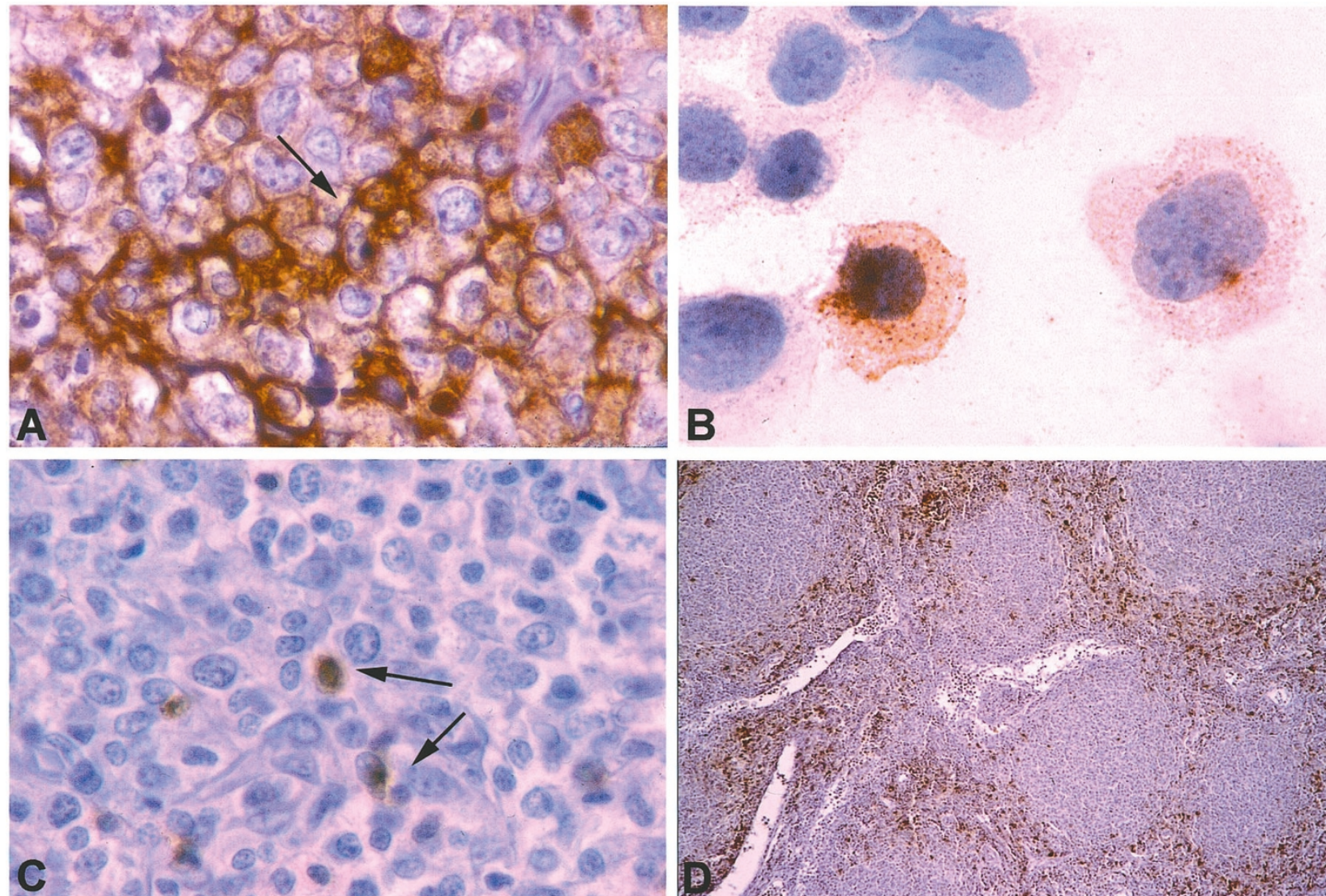

B
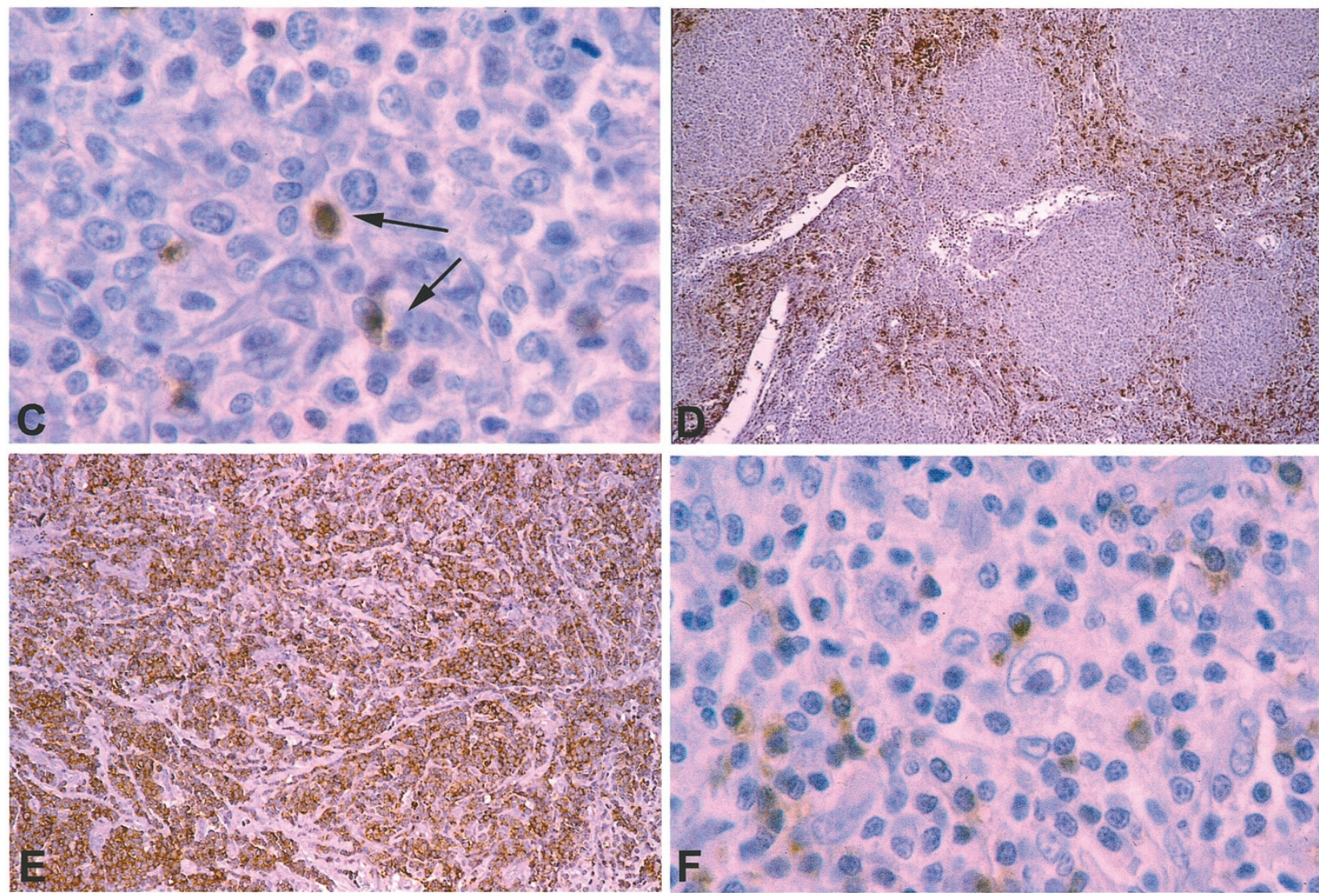

FIGURE 4. MAL protein expression in lymphoid malignancies. A, primary mediastinal large B-cell lymphoma stained for MAL showing membranous and occasionally paranuclear dotlike positivity (arrow) of virtually all tumor cells. B, primary mediastinal large B-cell lymphoma-derived B-cell line MedB-1 stained for MAL, showing positive tumor cells. C, nonmediastinal diffuse large B-cell lymphoma stained for MAL, showing that tumor cells are negative. Positive internal control represented by small lymphoid cells are present (arrows). D, follicular lymphoma stained for MAL showing that the tumor cells are negative and showing positive internal control in the interfollicular areas. E, Tlymphoblastic lymphoma strongly positive for MAL. F, classical Hodgkin lymphoma showing a negative Reed-Sternberg cell surrounded by positive small lymphocytes.

In T/NK cell neoplasms, most T-lymphoblastic lymphomas were positive, which is consistent with MAL initial description and MAL strong immunohistochemical expression in the thymic cortex, whereas all "mature" T-cell neoplasms were negative, except for one case of anaplastic large cell lymphoma.

As hematopathologists, we were concerned about the possibility of using MAL immunostaining to differentiate primary mediastinal large B-cell lym- phoma from classical Hodgkin lymphoma. With the advent of antigen retrieval methods, the immunophenotypic profile of some lymphoid malignancies has changed in the past few years. Seventy percent of primary mediastinal large B-cell lymphomas may express the Hodgkin marker CD30 (24), and expression of CD20 by Reed Sternberg cells is not a rare finding (25). It is possible to misdiagnose these two entities, which frequently present the same clinical features with a bulky mediastinal mass, especially 
when dealing with small biopsy samples. This may lead to an erroneous treatment and affect the overall survival rate, as emphasized in a recent study (26). MAL immunostaining may be useful for sorting out these "gray zone" lymphomas (23), but one must be aware of the potential of some classical Hodgkin lymphomas to express MAL, as 3 cases of our 31, all with a mediastinal tumor mass, displayed $20-50 \%$ positive Reed Sternberg cells. The reason for the occasional expression of MAL in classical Hodgkin lymphoma is unclear and raises the question of the possible thymic B-cell origin of Reed Sternberg cells, at least in some cases.

The biological significance of MAL protein expression in primary mediastinal large B-cell lymphoma tumor cells remains elusive. According to the literature, MAL proteolipid is a component of detergent-insoluble glycosphingolipid-enriched membrane microdomains, called lipid rafts, in $\mathrm{T}$ cells and in polarized epithelial cells and mature oligodendrocytes $(3-5,27)$. Functional studies performed in epithelial cell lines suggest that MAL has important functions in intracellular sorting and transport and in stabilization and maintenance of lipid raft membrane microdomains (7). In addition, in T cells, MAL co-immunoprecipitates with GPI-anchored proteins, like CD59, and $l c k$ tyrosine kinase, suggesting that MAL could serve as a linker protein between GPI-anchored proteins of the external leaflet of the plasma membrane and tyrosine kinases of the cytosolic leaflet and thus participate to T-cell signal transduction (10). Over the past few years, there has been growing evidence that lipid rafts play a key role in T-cell receptor (TCR) and B-cell receptor (BCR) signaling and trafficking (2831). In B cells, antigen binding induces BCR translocation into lipid rafts, where it encounters the signaling components necessary to initiate B-cell activation (32). Alteration of raft components in B cells may have important consequences, as illustrated by the EBV gene product LMP2A in EBV-immortalized B-cell lines. LMP2A is constitutively present in these B-cell rafts and blocks BCR signaling and internalization (32). Whether MAL is located in lipid rafts of primary mediastinal large B-cell lymphoma tumor cells and is involved in signaling in response to B-cell receptor ligation remains unknown at present. However, in view of MAL's supposed functions, it is tempting to speculate that MAL expression in a primary mediastinal large B-cell lymphoma's B cells may modify membrane raft dynamics and contribute to neoplastic cell dysregulation.

In conclusion, this study provides additional data on MAL expression in the lymphoid lineage. In physiologic conditions, MAL is found predominantly in the CD4 T-cell subset of peripheral blood lymphocytes, tonsil, and spleen and is not usually expressed in CD19+ B-cells. In the thymus, besides strong MAL expression in the cortex, a small fraction of thymic medullary B cells displays MAL immunoreactivity. These results further support thymic B cells as the normal counterpart of primary mediastinal large B-cell lymphomas and MAL as a distinct molecular marker of this lymphoma subtype among diffuse large B-cell lymphomas.

Acknowledgments: We gratefully acknowledge the following pathologists who provided pathological material: J. Brière, I. Abdalssamad, and E. Fernandez; and Y. Geleyn and N. Le Metayer for their technical assistance in flow cytometry and immunohistochemistry.

\section{REFERENCES}

1. Alonso MA, Weissman SM. cDNA cloning and sequence of MAL, a hydrophobic protein associated with human T-cell differentiation. Proc Natl Acad Sci U S A 1987;84:1997-01.

2. Schaeren-Wiemers N, Valenzuela DM, Frank M, Schwab ME. Characterization of a rat gene, rMAL, encoding a protein with four hydrophobic domains in central and peripheral myelin. J Neurosci 1995;15:5753-64.

3. Zacchetti D, Peranen J, Murata M, Fiedler K, Simons K. VIP17/MAL, a proteolipid in apical transport vesicles. FEBS Lett 1995;377:465-9.

4. Martin-Belmonte F, Kremer L, Albar JP, Marazuela M, Alonso MA. Expression of the MAL gene in the thyroid: the MAL proteolipid, a component of glycolipid-enriched membranes, is apically distributed in thyroid follicles. Endocrinology 1998;139:2077-84.

5. Millán J, Puertollano R, Fan L, Rancano C, Alonso MA. The MAL proteolipid is a component of the detergent-insoluble membrane subdomains of human T-lymphocytes. Biochem J 1997;321:247-52.

6. Puertollano R, Li S, Lisanti MP, Alonso MA. Recombinant expression of the MAL proteolipid, a component of glycolipid-enriched membrane microdomains, induces the formation of vesicular structures in insect cells. J Biol Chem 1997;272:18311-5.

7. Puertollano R, Martin-Belmonte F, Millán J, de Marco MC, Albar JP, Kremer L, et al. The MAL proteolipid is necessary for normal apical transport and accurate sorting of the influenzae virus hemagglutinin in Madin-Darby canine kidney cells. J Cell Biol 1999;145:141-51.

8. Cheong KH, Zacchetti D, Scheeberger EE, Simons K. VIP17/ MAL, a lipid raft-associated protein, is involved in apical transport in MDCK cells. Proc Natl Acad Sci USA 1999;96: 6241-8.

9. Martin-Belmonte F, Puertollano R, Millan J, Alonso MA. The MAL proteolipid is necessary for the overall apical delivery of membrane proteins in the polarized epithelial Madin-Darby canine kidney and Fischer rat thyroid cell lines. Mol Biol Cell 2000;11:2033-45.

10. Millán J, Alonso MA. MAL, a novel integral membrane protein of human $\mathrm{T}$ lymphocytes, associates with glycosylphosphatidylinositol-anchored proteins and Src-like tyrosine kinases. Eur J Immunol 1998;28:3675-84.

11. Copie-Bergman C, Gaulard P, Maouche-Chretien L, Brière J, Haioun C, Alonso MA, et al. The MAL gene is expressed in primary mediastinal large B-cell lymphomas. Blood 1999;94: 3567-75.

12. Harris NL, Jaffe ES, Stein H, Banks PM, Chan JCK, Clearly $\mathrm{ML}$, et al. A revised European-American classification of 
lymphoid neoplasms: a proposal from the International Lymphoma Study Group. Blood 1994;84:1361-92.

13. Rancano C, Rubio T, Correas I, Alonso MA. Genomic structure and subcellular localization of MAL, a human T-cellspecific proteolipid protein. J Biol Chem 1994;269:8159-64.

14. Rancano C, Rubio T, Alonso MA. Alternative splicing of human T-cell-specific MAL mRNA and its correlation with the exon/intron organization of the gene. Genomics 1994;21: 447-50.

15. Möller P, Brüderlein S, Sträter J, Leithäuser F, Hasel C, Bataille F, et al. MedB-1, a human tumor cell line derived from primary mediastinal large B-cell lymphoma. Int J Cancer 2001;92:348-53.

16. Jaffe ES, Harris NL, Stein H, Vardiman JW, editors. World Health Organization classification of tumours. Pathology and genetics of tumours of haematopoietic and lymphoid tissues. Lyon, France: IARC Press; 2001.

17. Isaacson PG, Norton AJ, Addis BJ. The human thymus contains a novel population of B lymphocytes. Lancet 1987;2: 1488-91.

18. Hofmann WJ, Momburg F, Möller P. Thymic medullary cells expressing B cell antigens. Hum Pathol 1988;19:1280-7.

19. Dunn-Walters DK, Howe CJ, Isaacson PGI, Spencer J. Location and sequence of rearranged immunoglobulin genes in human thymus. Eur J Immunol 1995;25:513-9.

20. Flores KG, LI J, Hale LP. B cells in epithelial and perivascular compartments of human adult thymus. Hum Pathol 2001; 32:926-34.

21. Möller P, Moldenhauer G, Momburg F, Lämmler B, EberleinGonska M, Kiesel S, et al. Mediastinal lymphoma of clear cell type is a tumor corresponding to terminal steps of B cell differentiation. Blood 1987;69:1087-95.

22. De Leval L, Ferry JA, Falini B, Shipp M, Harris NL. Expression of bcl-6 and CD10 in primary mediastinal large B-cell lymphoma. Evidence for derivation from germinal center B cells? Am J Surg Pathol 2001;25:1277-82.

23. Leithäuser F, Bäuerle M, Quang Huynh M, Möller P. Isotypeswitched immunoglobulin genes with a high load of somatic hypermutation and lack of ongoing mutational activity are prevalent in mediastinal B-cell lymphoma. Blood 2001;98: 2762-70.

24. Higgins JP, Warnke RA. CD30 expression is common in mediastinal large B-cell lymphoma. Am J Clin Pathol 1999;112: 241-7.

25. Rüdiger T, Jaffe ES, Delsol G, de Wolf-Peeters C, Gascoyne $\mathrm{RD}$, Georgii A, et al. Workshop report on Hodgkin's disease and related diseases ("grey zone" lymphoma). Ann Oncol 1998;9(Suppl 5):31-8.

26. Cazals-Hatem D, André M, Mounier N, Copin MC, Divine M, Berger $\mathrm{F}$, et al. Pathologic and clinical features of 77 Hodgkin's lymphoma patients treated in a lymphoma protocol (LNH87). A GELA study. Am J Surg Pathol 2001;25:297306.

27. Kim T, Fiedler K, Madison DL, Krueger WH, Pfeiffer SE. Cloning and characterization of MVP17: a developmentally regulated myelin protein in oligodendrocytes. J Neurosci Res 1995;42:413-22.

28. Gisou van der Goot F, Harder T. Raft membrane domains: from a liquid-ordered membrane phase to a site of pathogen attack. Semin Immunol 2001;13:89-97.

29. Carrie Miceli M, Moran M, Chung CD, Patel VP, Low T, Zinnanti W. Co-stimulation and counterstimulation: lipid raft clustering controls TCR signaling and functional outcomes. Semin Immunol 2001;13:115-28.

30. Leitenberg D, Balamuth F, Bottomly K. Changes in the T cell receptor macromolecular signaling complex and membrane microdomains during $\mathrm{T}$ cell development and activation. Semin Immunol 2001;13:129-38.

31. Alonso MA, Millán J. The role of lipid rafts in signalling and membrane trafficking in T lymphocytes. J Cell Sci 2001;114: 3957-65.

32. Cheng PC, Cherukuri A, Dykstra M, Malapati S, Sproul T, Chen MR, et al. Floating, the raft hypothesis: the role of lipid rafts in B cell antigen receptor function. Semin Immunol 2001;13:107-14. 